\title{
A sea-state based source function for size- and composition-resolved marine aerosol production
}

\author{
M. S. Long ${ }^{1}$, W. C. Keene ${ }^{1}$, D. J. Kieber ${ }^{2}$, D. J. Erickson ${ }^{3}$, and H. Maring ${ }^{4}$ \\ ${ }^{1}$ Department of Environmental Sciences, University of Virginia, Charlottesville, VA, USA \\ ${ }^{2}$ Department of Chemistry, College of Environmental Science and Forestry, State University of New York, \\ Syracuse, NY, USA \\ ${ }^{3}$ Computer Science and Mathematics Division, Oak Ridge National Laboratory, Oak Ridge, TN USA \\ ${ }^{4}$ NASA Headquarters: Radiation Sciences Program, Washington DC, USA
}

Received: 26 July 2010 - Published in Atmos. Chem. Phys. Discuss.: 28 September 2010

Revised: 20 January 2011 - Accepted: 27 January 2011 - Published: 14 February 2011

\begin{abstract}
A parameterization for the size- and compositionresolved production fluxes of nascent marine aerosol was developed from prior experimental observations and extrapolated to ambient conditions based on estimates of air entrainment by the breaking of wind-driven ocean waves. Production of particulate organic carbon $\left(\mathrm{OC}_{\mathrm{aer}}\right)$ was parameterized based on Langmuir equilibrium-type association of organic matter to bubble plumes in seawater and resulting aerosol as constrained by measurements of aerosol produced from productive and oligotrophic seawater. This novel approach is the first to parameterize size- and composition-resolved aerosol production based on explicit evaluation of wind-driven air entrainment/detrainment fluxes and chlorophyll- $a$ as a proxy for surfactants in surface seawater. Production fluxes were simulated globally with an eight aerosol-size-bin version of the NCAR Community Atmosphere Model (CAM v3.5.07). Simulated production fluxes fell within the range of published estimates based on observationally constrained parameterizations. Because the parameterization does not consider contributions from spume drops, the simulated global mass flux $\left(1.5 \times 10^{3} \mathrm{Tg} \mathrm{y}^{-1}\right)$ is near the lower end of published estimates. The simulated production of aerosol number $\left(1.4 \times 10^{6} \mathrm{~m}^{-2} \mathrm{~s}^{-1}\right)$ and $\mathrm{OC}_{\mathrm{aer}}\left(29 \mathrm{Tg} \mathrm{Cy}^{-1}\right)$ fall near the upper end of published estimates and suggest that primary marine aerosols may have greater influences on the physicochemical evolution of the troposphere, radiative transfer and climate, and associated feedbacks on the surface ocean than suggested by previous model studies.
\end{abstract}

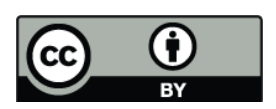

Correspondence to: M. S. Long (msl3v@virginia.edu)

\section{Introduction}

Particle production by bursting bubbles at the air-sea interface is the dominant global source of aerosol mass and a major global source of aerosol number (Andreae and Rosenfeld, 2008). Primary marine aerosol is an important compositiondependent reaction medium that influences an interrelated set of processes including the phase partitioning and associated atmospheric lifetimes of soluble gases and the multiphase chemical and physical evolution of marine air (von Glasow and Crutzen, 2004; Keene et al., 2009). Direct measurements of organic carbon associated with marine aerosols produced artificially in chamber experiments (Hoffman and Duce, 1976; Keene et al., 2007; Facchini et al., 2008) and with aerosols in ambient air over the open ocean (e.g., O'Dowd et al., 2008) indicate that, under most conditions, nascent marine aerosols are highly enriched relative to seawater (typically by 2 to 3 orders of magnitude based on bulk composition) in marine-derived organic material. However, organic contents inferred from thermal desorption measurements of aerosols produced artificially from coastal seawater (Modini et al., 2010) and generated naturally from coastal surf (Clarke et al., 2006) suggest lower enrichments. Causes for these differences are not known. Manipulation experiments indicate that the chemical processing of marinederived particulate organic material is a major source of the $\mathrm{OH}$ radical and a likely suite of important low molecular weight reaction products including carboxylic acids, ketones, and alcohols (Zhou et al., 2008). Primary marine aerosols also scatter incident solar radiation and account for a significant fraction of cloud condensation nuclei (CCN) over the world's oceans thereby influencing Earth's radiative balance and climate (Clarke et al., 2006). 
Despite their global significance, the size-resolved physical (mass and number) and chemical (organic and inorganic) characteristics and production fluxes of primary marine aerosols are not adequately parameterized in comprehensive Earth system models as functions of major drivers (wind velocity and the chemical composition of surface seawater). Some parameterizations are based on measurements in ambient air, which are advantageous in that they directly relate variability in production rates inferred from ambient concentrations to the corresponding environmental drivers (e.g. wind speed). These include parameterizations inferred from measured number size distributions in near-surface marine air (Gong et al., 2002; Gong, 2003), vertical gradients in number size distributions measured immediately down wind of coastal surf (Clarke et al., 2006), eddy covariance measurements of sub- $\mu \mathrm{m}$ number concentrations during onshore flow (Geever et al., 2005), and associated measurements of ambient aerosol composition (O'Dowd et al., 2008). However, these and other measurement techniques cannot quantify, at high temporal resolution, the size-resolved composition of primary marine aerosol produced by bursting bubbles over the full relevant size range (10-nm to $30-\mu \mathrm{m}$ ambient diameter). In addition, the initial composition of nascent marine aerosol changes rapidly (seconds to minutes) via exposure to light and reactive trace gases (Chameides and Stelson, 1992; Erickson et al., 1999; Zhou et al., 2008). Consequently, it is extremely difficult to reliably deconvolute the characteristics of fresh versus processed aerosols based on ambient-air measurements.

Other recently published parameterizations have been developed based on aerosols generated artificially by bubbling air through natural or artificial seawater or impinging a water jet on surface seawater. However, some of these studies consider only the sub- $\mu \mathrm{m}$-diameter size fractions (Sellegri et al., 2006; Tyree et al., 2007; Hultin et al., 2010; Fuentes et al., 2010) thereby ignoring the larger aerosols that dominate mass and volume flux. Another study based on artificially generated aerosols employs synthetic seawater of unreported organic content (Mårtensson et al., 2003) and associated implications for aerosol characteristics. The reader is referred to Hultin et al. (2010) for an intercomparison of normalized number size distributions reported by different investigators. Spatial and temporal variability in the production and impacts of size-resolved marine aerosols have also been simulated globally using models configured with some of the above parameterizations (e.g., Pierce and Adams, 2006; Langmann et al., 2008; Roelofs, 2008; Spracklen et al., 2008; Gantt et al., 2009; Vignati et al., 2010).

We report herein a new parameterization for the sizeresolved production and physicochemical characteristics of nascent marine aerosol as functions of air detrainment through, and the chemical composition of, the surface seawater column. This approach is based on measured characteristics of size-resolved aerosols over full size distributions that were produced via the detrainment of artificially gener- ated bubbles from fresh, flowing seawater under controlled conditions (Keene et al, 2007; Facchini et al, 2008). This parameterization is part of a larger effort to develop, within the Community Atmosphere Model (CAM) component of the NCAR Community Climate System Model (CCSM), a more explicit description of the sources, multiphase processing, and climatic interactions of naturally produced aerosols.

\section{Parameterization}

To facilitate application by other investigators and to provide context for its derivation, the complete parameterization is presented in Appendix A. The underlying data, associated rationale for the approach, intermediate steps, definitions, and units are detailed below.

\subsection{Size-resolved number production flux}

Observations indicate that the total number production flux of nascent marine aerosols $\left(F_{\mathrm{T}} ; \mathrm{m}^{-2} \mathrm{~s}^{-1}\right)$ via bursting bubbles at the seawater surface is linearly proportional to the flux of air detrained from the water column (Keene et al., 2007), which implies that the ratio of particles produced per unit volume of air detrained is approximately constant. Therefore, assuming all air entrained into the water column detrains as bubbles that produce particles, the number production flux of marine aerosol can be estimated from the corresponding entrainment flux of air into the water column $\left(F_{\text {Ent }}\right.$, in $\left.\mathrm{m}^{3} \mathrm{~m}^{-2} \mathrm{~s}^{-1}\right)$. The dissipation of wave energy by wave breaking involves work against the buoyant force of air entrained into the water column. Measurements demonstrate that the volume of air entrained within the water column by breaking waves $\left(V_{0}\right.$ in $\left.\mathrm{m}^{3}\right)$ is proportional to the energy dissipated by the wind-wave field through wave breaking $\left(E_{\mathrm{D}}\right.$ in J; Lamarre and Melville, 1991; Loewen and Melville, 1993; Hoque, 2002; Blenkinsopp and Chaplin, 2007). Although the physical characteristics of plunging versus spilling breakers differ (e.g., Lewis and Schwartz, 2004), available evidence suggests that the $V_{0}$-to- $E_{\mathrm{D}}$ ratio (heretofore referred to as $\alpha$ ) varies across a narrow range for both types of breakers. For example, measurements of $V_{0}$ and $E_{\mathrm{D}}$ for 2-D plunging breakers (Lamarre and Melville,1991) yield $\alpha$ values of 5.6 $( \pm 0.2) \times 10^{-4} \mathrm{~m}^{3} \mathbf{J}^{-1}$ (number of samples $(n)=3$ ). Similar measurements for both 2-D plunging and spilling breakers by Blenkinsopp and Chaplin (2007) yield $\alpha$ values of 2.2 $( \pm 0.2) \times 10^{-4} \mathrm{~m}^{3} \mathrm{~J}^{-1}\left(n \approx 10^{3}\right)$. For the latter study, $V_{0}$ is based on the maximum observed volume of air entrained during the breaking event. Because some air may be detrained before or entrained after the observed maximum measured volume (C. Blenkinsopp, Univ. New South Wales, personal communication, 2010), we infer that $\alpha$ values based on Blenkinsopp and Chaplin (2007) correspond to lower limits. 
$F_{\text {Ent }}$ can be estimated from

$F_{\text {Ent }}=\alpha \varepsilon_{\mathrm{d}}$

where $\varepsilon_{\mathrm{d}}$ is the rate of energy dissipation by wave breaking $\left(\mathrm{W} \mathrm{m}^{-2}\right)$. Hanson and Phillips (1999) showed that $\varepsilon_{\mathrm{d}}$ varied as a power-law function of 10 -m wind speed $U_{10}\left(\right.$ in $\mathrm{m} \mathrm{s}^{-1}$ ), $\varepsilon_{\mathrm{d}} \approx 4.28 \times 10^{-5} \cdot U_{10}^{3.74}$ (uncertainties were not reported). $\varepsilon_{\mathrm{d}}$ values reported by Felizardo and Melville (1995) yielded a similar wind-speed dependence for $F_{\text {Ent }}$, although $\varepsilon_{\mathrm{d}}$ values were higher by $30 \%$ to $40 \%$ (see Hanson and Phillips, 1999).

Based on the available albeit limited measurements summarized above, we estimate that values of $\alpha$ and $\varepsilon_{\mathrm{d}}$ fall within the ranges of $4( \pm 2) \times 10^{-4} \mathrm{~m}^{3} \mathrm{~J}^{-1}$ and $5( \pm 1) \times 10^{-5}$. $U_{10}^{3.74} \mathrm{~W} \mathrm{~m}^{-2}$, respectively, giving

$F_{\text {Ent }}=2( \pm 1) \times 10^{-8} \cdot U_{10}^{3.74}$

Uncertainties are based on reported values or, when not reported, reasonable estimates.

We assume that the relationship described by Eq. (2) remains constant across the global wind-wave field. The similarity in the fraction of $\varepsilon_{\mathrm{D}}$ attributed to entrainment in previous studies (e.g. Melville and Rapp, 1985; Loewen and Melville, 1993; Hoque, 2002) supports this assumption over the range of wind-wave conditions that have been evaluated. We recognize that the assumption may not be valid under the more energetic wind-wave conditions at higher wind speeds $\left(>20 \mathrm{~m} \mathrm{~s}^{-1}\right)$. However, physical characteristics of breaking wave fields and associated particle fluxes at high sea states are poorly constrained and, consequently, Eq. (2) cannot be evaluated explicitly under these relatively infrequent model conditions (discussed in more detail below).

Physicochemical characteristics of nascent marine aerosols vary systematically as a function of size (Lewis and Schwartz, 2004; Keene et al., 2007). Super- $\mu$ m size fractions dominate the volume of fresh marine aerosol with non-water masses that are comprised primarily of inorganic sea salt. Sub- $\mu \mathrm{m}$ size fractions dominate the corresponding number concentrations and contain increasing amounts of $\mathrm{OC}_{\mathrm{aer}}$ with decreasing size. One- $\mu$ m diameter at $80 \%$ relative humidity $(\mathrm{RH})$ represents the approximate partition between the upper end of the number-size distribution and the lower end of the volume-size distribution (Keene et al., 2007). To maximize resolution in parameterized production of both aerosol number and mass, the total number production fluxes reported by Keene et al. (2007) were binned into two size modes hereafter referred to as mode- 1 and mode- 2 and denoted with subscripts 1 and 2, respectively). Size ranges for mode- 1 and mode- 2 particles were $0.044-$ to $1.0-\mu \mathrm{m}$ and 1.0- to $24.0-\mu \mathrm{m}$ diameter at $80 \% \mathrm{RH}$, respectively, and are denoted $R_{1}$ and $R_{2}$, respectively.

Keene et al. (2007) measured the size-resolved number fluxes of mode-2 particles with an aerodynamic particle sizer (APS) and also sampled the corresponding size-resolved mass fluxes with cascade impactors and quantified the ionic composition by ion chromatography and total organic carbon by high-temperature combustion. To properly implement mode-2 fluxes in the parameterization reported herein, we evaluated the internal consistency of measurements reported by Keene et al. (2007) as follows. Size- and compositionresolved mass fluxes of mode- 2 particles were converted to number fluxes at $80 \% \mathrm{RH}$ following Keene et al. (2007) and compared with the corresponding size-resolved number fluxes measured directly with the APS (Fig. 1). The excellent agreement over most of the super- $\mu \mathrm{m}$ size range suggests that both the size-resolved number concentrations and masses were accurately measured. The divergence in fluxes of particles greater than $\sim 12-\mu$ m diameter resulted from losses of larger deliquesced particles within the APS via gravitational settling and impaction. Consequently, the parameterization of number production fluxes for particles greater than 12$\mu \mathrm{m}$ diameter at $80 \% \mathrm{RH}$ was based on those calculated from the mass data whereas parameterization of fluxes for smaller super- $\mu$ m diameter particles was based on those measured directly with the APS.

Keene et al. (2007) showed that the total number production fluxes of mode- 1 and mode- 2 particles $\left(F_{1}\right.$ and $F_{2}$, respectively, in $\left.\mathrm{m}^{-2} \mathrm{~s}^{-1}\right)$ are linearly proportional to the air detrainment flux through the water column $\left(F_{\text {Det }}\right.$ in $\left.\mathrm{m}^{3} \mathrm{~m}^{2} \mathrm{~s}^{-1}\right)$, or

$$
F_{\mathrm{T}}=\sum_{N=1}^{2} F_{\mathrm{N}}=F_{\text {Det }} \cdot \sum_{N=1}^{2} c_{\mathrm{N}}
$$

$c_{\mathrm{N}}\left(\mathrm{m}^{-3}\right)$ is a wind-speed-invariant parameter describing the particle production rate per unit air detrained with the form $c_{N}=\int_{R_{\mathrm{N}}} f_{\mathrm{N}}\left(\log D_{\mathrm{P}}\right) d \log D_{\mathrm{P}}$ where $f_{\mathrm{N}}$, in units of $\mathrm{m}^{-3}$, is a function of $\log D_{\mathrm{P}}$ (defined below). Hultin et al. (2010) present evidence suggesting a wind-speed dependence for $c_{\mathrm{N}}$ that may reflect changes in the water-column affecting particle production; this dependence is not considered here.

Based on the assumptions that all air entrained by wave action is detrained as bubbles that produce particles $\left(F_{\text {Ent }}=\right.$ $\left.F_{\text {Det }}\right)$, and that bubble plumes for breaking waves of different sizes have similar bubble size distributions (e.g. see Deane, 1997), then for mode $N$,

$F_{\mathrm{N}}\left(U_{10}, \log D_{\mathrm{P}}\right)=F_{\mathrm{Ent}}\left(U_{10}\right) \cdot \int_{R_{\mathrm{N}}} f_{\mathrm{N}}\left(\log D_{\mathrm{P}}\right) d \log D_{\mathrm{P}}$

Because some bubbles dissolve and others detrain as large voids (Lamarre and Melville, 1991) that presumably produce relatively few particles per unit volume of air, aerosol production fluxes based on Eq. (3) are considered upper limits. Third order polynomials were fit to the size-resolved production fluxes measured by Keene et al. (2007) based on least squares regression to yield continuous functions of the form

$f_{\mathrm{N}}\left(\log D_{\mathrm{P}}\right)=10^{P_{\mathrm{N}}}$ 


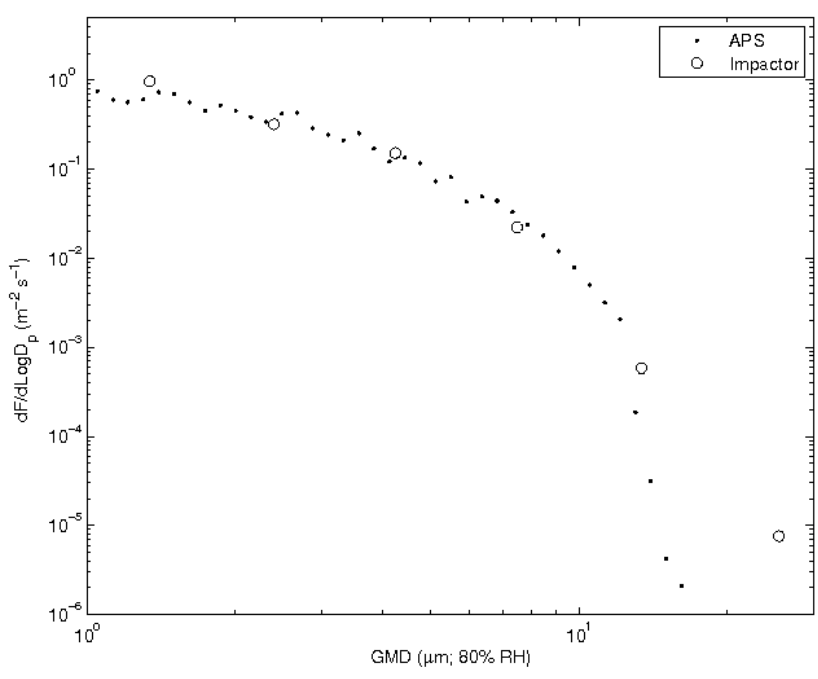

Fig. 1. Number production fluxes of artificially generated aerosols measured with an APS (solid diamonds) and the corresponding number production fluxes calculated from size-resolved aerosol mass sampled with a cascade impactor and analyzed by ion chromatography (open circles).

where $D_{\mathrm{P}}$ is the deliquesced particle diameter in $\mu \mathrm{m}$ at $80 \% \mathrm{RH}$ and $P_{\mathrm{N}}$ are the polynomials

$$
\begin{gathered}
P_{1}\left(\log D_{\mathrm{P}}\right)=2.87 \cdot\left(\log D_{\mathrm{P}}\right)^{3}+3.40 \cdot\left(\log D_{\mathrm{P}}\right)^{2} \\
-1.04 \cdot\left(\log D_{\mathrm{P}}\right)+8.92
\end{gathered}
$$

and

$$
\begin{aligned}
& P_{2}\left(\log D_{\mathrm{P}}\right)=-1.53 \cdot\left(\log D_{\mathrm{P}}\right)^{3}-8.10 \times 10^{-2} \cdot\left(\log D_{\mathrm{P}}\right)^{2} \\
& \quad-4.26 \times 10^{-1} \cdot\left(\log D_{\mathrm{P}}\right)+8.84
\end{aligned}
$$

for mode- 1 and mode- 2 particles, respectively. The corresponding correlation coefficients $(r)$ are 0.99 and 0.99 , respectively. Based on James and Lang (1971), 4th-order polynomials yield marginally better fits to the data relative to 3 rd order polynomials but 3rd-order relationships were employed in the parameterization for their smaller computational footprint. See Supplement for a comparison of the 3rd and 4th order polynomial fits to the data. Following convention, the flux for a given diameter interval can be expressed as a flux per logarithmic diameter interval, $d \log D_{\mathrm{P}}=\log \left(D_{\mathrm{P}, \text { UpperLimit }}\right)-\log \left(D_{\mathrm{P}, \text { LowerLimit }}\right)$, giving the final form of the total particle flux function at $80 \% \mathrm{RH}$ as

$$
\frac{d F_{\mathrm{N}}}{d \log D_{\mathrm{P}}}=F_{\mathrm{Ent}} \cdot 10^{P_{\mathrm{N}}}
$$

For example, at a $U_{10}$ of $9 \mathrm{~m} \mathrm{~s}^{-1}$ and a RH of $80 \%$, the above algorithm yields mode- 1 and mode- 2 particle fluxes of $7.1 \times 10^{5} \mathrm{~m}^{-2} \mathrm{~s}^{-1}$ and $2.1 \times 10^{4} \mathrm{~m}^{-2} \mathrm{~s}^{-1}$ for $D_{\mathrm{P}}$ values of 0.3 and $3.0 \mu \mathrm{m}$, respectively. Based on variances for replicate measurements at $80 \% \mathrm{RH}$ reported by Keene et al. (2007), $f_{1}\left(\log D_{\mathrm{P}}\right)$ is uncertain by a factor of $\pm 21 \%$ and $f_{2}\left(\log D_{\mathrm{P}}\right)$ by a factor of $\pm 84 \%$ (uncertainty for all data, $f_{1}$ and $f_{2}$ combined, is $\pm 40 \%)$. Minor variability in RH and the composition of feed seawater over the period of characterization coupled with random measurement errors contributed to variability in replicate measurements of production rates under otherwise identical conditions (Keene et al., 2007). Other major sources of uncertainty are discussed at the end of Sect. 4.

\subsection{Production flux of particulate organic matter}

Keene et al. (2007) and Facchini et al. (2008) measured sizeresolved concentrations of inorganic sea salt and $\mathrm{OC}_{\mathrm{aer}}$ associated with nascent marine aerosols produced via the detrainment of artificially generated bubbles from flowing oligotrophic and eutrophic seawater, respectively. Facchini et al. (2008) quantified total $\mathrm{OC}_{\mathrm{aer}}$ whereas Keene et al. (2007) measured $\mathrm{OC}_{\mathrm{aer}}$ recovered via vigorous sequential extractions in deionized water of nascent aerosols sampled on filters. Analysis of sequential extract solutions suggests that $\mathrm{OC}_{\mathrm{aer}}$ was recovered quantitatively. However, because the filters may have retained minor fractions of tightly bound insoluble organic compounds, data reported by Keene et al. (2007) are considered lower limits. The two studies also employed different factors to account for the associated $\mathrm{H}$ and $\mathrm{O}$ when converting the measured mass of $\mathrm{OC}_{\text {aer }}$ to the corresponding mass of organic matter $\left(\mathrm{OM}_{\mathrm{aer}}\right)$. Facchini et al. (2008) used factors of 1.8 and 1.4 for water-soluble and water-insoluble fractions, respectively, based on Decesari et al. (2007) whereas Keene et al. (2007) used a factor of 2.0 based on Turpin and Lim (2001). Our parameterization is based on the $\mathrm{OM}_{\mathrm{aer}}$ masses as reported in the two articles. This difference implies a corresponding uncertainty factor of $\sim \pm 0.4$ in simulated $\mathrm{OC}_{\mathrm{aer}}$ production fluxes.

The range in total number production fluxes evaluated by Keene et al. (2007) $\left(2.1 \times 10^{7}\right.$ to $\left.10.5 \times 10^{7} \mathrm{~m}^{-2} \mathrm{~s}^{-1}\right)$ bracket the mean flux reported by Facchini et al. (2008) $\left(2.5( \pm 0.7) \times 10^{7} \mathrm{~m}^{-2} \mathrm{~s}^{-1}\right)$, which suggests similar bubble plume characteristics in both sets of experiments. Drawing on the above observations, we developed a preliminary parameterization of $\mathrm{OM}_{\mathrm{aer}}$ in the source function based on the assumption that the scavenging of surface-active organic matter in seawater $\left(\mathrm{OM}_{\text {sea }}\right)$ by bubbles from breaking waves varies as a function of the surface area concentration of the bubble plume based on Langmuir equilibria, which relate the amount of surfactant adsorbed to a surface, the available surface-area concentration, and the concentration of surfactant in seawater. Considerable experimental evidence supports this theoretical framework (e.g. Stefan and Szeri, 1999; Ghosh, 2004; Giribabu and Ghosh, 2007). However, available information precludes explicit evaluation of variability in the partitioning of organics adsorbed onto bubble surfaces versus $\mathrm{OM}_{\text {sea }}$ as a function of the air entrainment flux. For a given $\mathrm{OM}_{\text {sea }}$, we assume that partitioning does not vary significantly as a function of air flux. Scavenging by bubble 
plumes is limited to the top one to three $m$ of the ocean (Thorpe, 1982) whereas the corresponding mixed layer (and presumably $\mathrm{OM}_{\text {sea }}$ ) typically extends to depths on the order of 10 to $100 \mathrm{~m}$. Consequently, it is likely that $\mathrm{OM}_{\text {sea }}$ rather than bubble plume surface area concentration is the primary factor that regulates partitioning under most conditions. We assume further that the functional relationship between $\mathrm{OM}_{\text {sea }}$ and the fraction thereof scavenged by subsurface bubbles is retained in the $\mathrm{OM}_{\mathrm{aer}}$ that is produced when those bubble burst (i.e., the size-resolved production of $\mathrm{OM}_{\mathrm{aer}}$ scales proportionately with the amount of $\mathrm{OM}_{\text {sea }}$ scavenged by bubble surfaces).

Based on the assumption that all $\mathrm{OM}_{\mathrm{aer}}$ is internally mixed with deliquesced inorganic sea salt (i.e., associated with the same particles), then, for a given air detrainment flux, variability in $\mathrm{OM}_{\mathrm{aer}}$ would influence the shape of the number size distribution but not the total number flux, which would remain constant. Potential influences of $\mathrm{OM}_{\text {sea }}$ on bubble dynamics or the corresponding aerosol production fluxes are not considered explicitly. Due to the significant size-dependent contribution of $\mathrm{OM}_{\mathrm{aer}}$ to mass and volume of mode-1 particles, the size distribution described by Eq. (5) does not represent a lower boundary condition for an organic carbon-dependent function (i.e. Eq. (5) is based on data for which $\mathrm{OM}_{\mathrm{aer}}$ is nonzero). If $\mathrm{OM}_{\mathrm{aer}}$ were removed from the particle population that was measured by Keene et al. (2007) (on which Eq. 5 is based), the distribution would shift to smaller size. To quantify the lower boundary condition in the

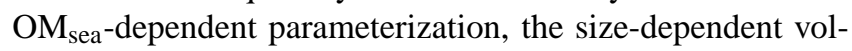
ume corresponding to $\mathrm{OM}_{\mathrm{aer}}$ was subtracted from the measured size distribution to yield the size distribution corresponding to pure deliquesced sea salt devoid of $\mathrm{OM}_{\mathrm{aer}}$. The calculated volume of organic matter is based on an assumed density of $1.1 \mathrm{~g} \mathrm{~cm}^{-3}$ (Schkolnik et al., 2006). The resulting geometric mean diameter (GMD at $80 \% \mathrm{RH}$ ) for the smallest size fraction measured by Keene et al. (2007) decreased from $0.13 \mu \mathrm{m}$ to $0.10 \mu \mathrm{m}$. Based on the assumption that $\mathrm{OM}_{\mathrm{aer}}$ does not influence hygroscopicity (Keene et al., 2007), the modified polynomial regression $(r=0.99)$ that incorporates the lower boundary condition $\left(\mathrm{OM}_{\mathrm{aer}}=0\right)$ for the size-resolved production flux of mode-1 aerosols (Eq. 5) is

$$
\begin{aligned}
& P_{1}\left(\log D_{\mathrm{P}}, \mathrm{OM}_{\text {sea }}\right)=1.46 \cdot\left(\log D_{\mathrm{P}}^{\prime}\right)^{3}+1.33 \cdot\left(\log D_{\mathrm{P}}^{\prime}\right) 2 \\
& -1.82 \cdot\left(\log D_{\mathrm{p}}^{\prime}\right)+8.83
\end{aligned}
$$

where

$D_{\mathrm{P}}^{\prime}=\sqrt[3]{\frac{\omega^{3}}{\omega^{3}+\delta_{\mathrm{N}}}} \cdot D_{\mathrm{P}}$

and

$\delta_{\mathrm{N}}=\frac{V_{\mathrm{OM}}}{V_{\mathrm{SS}}}$
$V_{\mathrm{OM}}$ is the volume of organic matter per particle in $\mu \mathrm{m}^{3}$ estimated as described above, $V_{\mathrm{SS}}$ is the corresponding volume of dry sea-salt in $\mu^{3}$ based on an assumed density of $2.165 \mathrm{~g} \mathrm{~cm}^{-3}, \omega$ is a hygroscopicity parameter relating the diameter of a dry sea-salt particle ( $\left.D_{\mathrm{SS}}\right)$ to sea-salt deliquesced at $80 \% \mathrm{RH}\left(D_{80}\right)$, such that $D_{80}=D_{\mathrm{P}}^{\prime}=\omega D_{\mathrm{SS}}$ and $V_{\mathrm{P}}=\omega^{3} V_{\mathrm{SS}}+V_{\mathrm{OM}}$, where $V_{\mathrm{P}}$ is the total volume of a particle at $80 \% \mathrm{RH}$ with diameter $D_{\mathrm{P}}$. $\omega$ is assumed to be 2 (Lewis and Schwartz, 2004).

Conceptually, $\delta_{\mathrm{N}}$ for both mode- 1 and -2 particles is limited by the saturation of bubble surface area by $\mathrm{OM}_{\text {sea. }}$. However, different approaches were required to account for the size dependent variability within each mode.

For mode-1 particles, there were sufficient data to derive a size-resolved expression for $\delta_{1}$. Measurements reported by Keene et al. (2007) and Facchini et al. (2008) show that the mass and volume ratios of organic matter to inorganic sea salt increase with decreasing particle size from values near zero at the upper end of the mode- 1 size distribution to values in the range of seven for the smallest measured size fractions. To account for this variability over the full mode- 1 size distribution, we adopt an empirical function of the form

$\delta_{1}\left(D_{\mathrm{p}}, \mathrm{OM}_{\mathrm{sea}}\right)=B_{1} \cdot D_{\mathrm{p}}^{\gamma_{1}}$

where $B_{1}$ is an empirical constant, and $\gamma_{1}$ is a Langmuirdriven shape parameter calculated for mode 1 aerosols from

$\gamma_{1}=\frac{\gamma_{\mathrm{m}, 1} \cdot K_{1} \cdot \mathrm{OM}_{\mathrm{sea}}}{1+K_{1} \cdot \mathrm{OM}_{\mathrm{sea}}}$

$\gamma_{\mathrm{m}, 1}$ corresponds to the saturation constant and $K_{1}$ is analogous to the adsorption equilibrium constant for $\mathrm{OM}_{\text {sea }}$ in the classic Langmuir formulation (e.g., see Stumm and Morgan, 1996). In the present formulation, both constants are unitless.

Mode-2 particles exhibited no statistically discernible size dependence for $\mathrm{OM}_{\mathrm{aer}}$. Consequently, for $\delta_{2}$, a bulk Langmuir approach was employed using

$\delta_{2}=\frac{\delta_{\mathrm{m}, 2} \cdot K_{2} \cdot \mathrm{OM}_{\text {sea }}}{1+K_{2} \cdot \mathrm{OM}_{\mathrm{sea}}}$

where $\delta_{\mathrm{m}, 2}$ is the saturation value for the volume ratio of organic matter to dry sea salt and $K_{2}$ is analogous to the corresponding absorption equilibrium constant; both constants are unitless.

The behavior of the Langmuir isotherm is such that at sufficiently high $\mathrm{OM}_{\mathrm{sea}}, \gamma_{1} \rightarrow \gamma_{\mathrm{m}, 1}$ and $\delta_{2} \rightarrow \delta_{\mathrm{m}, 2}$ for mode- 1 and mode- 2 aerosol, respectively.

Chlorophyll-a (chl- $a$ in $\mu \mathrm{g} \mathrm{L}^{-1}$ ) was adopted as a proxy for $\mathrm{OM}_{\text {sea }}$ based on the assumption that chl- $a$ and $\mathrm{OM}_{\text {sea }}$ concentrations in seawater are correlated. This assumption is supported by measurements of surfactants and chl- $a$ in seawater (e.g. Zutic and Legovic, 1990), seasonal covariability in chl- $a$ in seawater and $\mathrm{OC}_{\mathrm{aer}}$ in ambient marine aerosols (O'Dowd et al., 2004), and lower production rates of nascent $\mathrm{OC}_{\mathrm{aer}}$ from oligotrophic seawater containing low 
Table 1. Mass ratios expressed as percentages of mean $\mathrm{OM}_{\mathrm{aer}}$ to inorganic sea salt for bulk and mode-2 aerosol and corresponding mean chl- $a$ concentrations in surface seawater. Uncertainties correspond to reported variability in measurements.

\begin{tabular}{lccc}
\hline & $\begin{array}{c}\text { Mass Ratio for OMaer to } \\
\text { Sea Salt in Bulk Aerosol }\end{array}$ & $\begin{array}{c}\text { Mass Ratio for OMaer to } \\
\text { Sea Salt in Mode-2 Aerosol }^{\mathrm{b}}\end{array}$ & $\begin{array}{c}\text { chl- } a \\
\left(\mu \mathrm{g} \mathrm{L}{ }^{-1}\right)\end{array}$ \\
\hline Keene et al. (2007) & $2.5 \% \pm 2.0 \%$ & $1.5 \% \pm 1.1 \%$ & 0.055 \\
Facchini et al (2008) & $4.5 \% \pm 0.2 \%^{\mathrm{c}}$ & $2.7 \% \pm 0.2 \%^{\mathrm{c}}$ & 1.4 \\
\hline
\end{tabular}

a Based on measured $\mathrm{OM}_{\mathrm{aer}}$ and inorganic sea-salt mass for size-resolved aerosol summed over all size fractions and for aerosol sampled in bulk.

${ }^{\mathrm{b}}$ Based on measured $\mathrm{OM}_{\mathrm{aer}}$ and inorganic sea-salt mass summed over super- $\mu \mathrm{m}$ size fractions at $80 \% \mathrm{RH}$.

c Provided by M.C. Facchini (Institute of Atmospheric Sciences and Climate, CNR, Bologna, Italy, unpublished data, 2008).

chl- $a$ (Keene et al., 2007) relative to higher production rates of nascent $\mathrm{OC}_{\mathrm{aer}}$ from productive seawater containing high chl- $a$ (Facchini et al., 2008). Substituting chl- $a$ for $\mathrm{OM}_{\text {sea }}$ in Eqs. (12) and (13) yields

$\gamma_{1}=\frac{\gamma_{\mathrm{m}, 1} \cdot k_{1} \cdot[\mathrm{chl}-a]}{1+k_{1} \cdot[\operatorname{chl}-a]}$

and

$\delta_{2}=\frac{\delta_{\mathrm{m}, 2} \cdot k_{2} \cdot[\mathrm{chl}-a]}{1+k_{2} \cdot[\operatorname{chl}-a]}$

respectively, where $k_{1}$ and $k_{2}$ are the corresponding absorption equilibrium constants based on chl- $a$.

Because dissolved organic carbon in seawater (DOC) does not correlate with either chl- $a$ or $\mathrm{OM}_{\mathrm{aer}}$, DOC was not considered to be a reasonable proxy for $\mathrm{OM}_{\text {sea }}$. This lack of correlation reflects the fact that DOC is composed of a mixture of labile, semilabile, and recalcitrant compounds that originate from multiple sources, are lost via different pathways, and exhibit variable lifetimes against degradation (see Carlson et al., 1994; Doval and Hansell, 2000). We emphasize that the approach of using chl- $a$ as a proxy for $\mathrm{OM}_{\text {sea }}$ in the production parameterization is based on results of only two studies and anticipate that the parameterization will be refined as additional simultaneous measurements of chl- $a$, $\mathrm{DOC}, \mathrm{OM}_{\text {sea }}$, nascent $\mathrm{OM}_{\mathrm{aer}}$, and the corresponding speciation thereof become available.

For $\delta_{1}$, the three dimensionless constants in Eqs. (11), (14) and (15) $\left(B_{1}, \gamma_{\mathrm{m}, 1}\right.$, and $\left.k_{1}\right)$ were determined as follows. The mean chl- $a$ concentrations in feed seawater and the corresponding size-resolved mass ratios of $\mathrm{OM}_{\mathrm{aer}}$ to sea salt measured by Keene et al. (2007) and Facchini et al. (2008) (Table 1) were used to calculate individual $\delta_{1}$ values for each size faction in the two datasets based on Eq. (10). Regressing the resulting $\delta_{1}$ values against $D_{\mathrm{P}}$ based on Eq. (11) yielded $B_{1}$ values of 0.277 and 0.335 and $\gamma$ values of -1.38 and -1.97 for Keene et al. (2007) and Facchini et al. (2008), respectively. Based on the above values and using a mean $B_{1}$ value of 0.306 , we found $\gamma_{\mathrm{m}}$ of -2.01 and $K_{1}$ of 40.0 by solving Eq. (14) using the method of Scatchard (1942).

Mean values for chl- $a$ and the mass ratios of $\mathrm{OM}_{\text {aer }}$ to sea salt for mode-2 aerosols (Table 1) were used to empirically constrain $\delta_{2}$. Again using the method of Scatchard (1942), Eq. (15) was solved for $\delta_{\mathrm{m}, 2}$ and $k_{2}$ yielding 0.056 and 20.8, respectively. The relatively small contributions of $\mathrm{OM}_{\mathrm{aer}}$ to the volume of mode- 2 particles corresponded to negligible differences in the size distribution described by Eq. (6). Therefore, substituting the $D_{\mathrm{P}}^{\prime}$ transformation (Eq. 9) for $D_{\mathrm{P}}$, Eq. (6) was used as the lower boundary condition $\left(\mathrm{OM}_{\text {sea }}=\right.$ 0 ) for the mode- 2 parameterization. The OM adsorption parameters for mode- 1 and mode- 2 aerosol are summarized in Table 2.

\section{Global simulations}

Size-resolved number and mass production fluxes based on the parameterization derived above (as presented in Appendix A, and hereafter referred to as Long10) were simulated offline (i.e. with no feedbacks involving the atmospheric system) over five years using an 8-aerosol sizebin version (3.5.07) of the NCAR Community Atmosphere Model at $1.9^{\circ} \times 2.5^{\circ}$ lat-long resolution (Gent et al., 2009). The atmosphere model was initialized at 1 January 2000. Interfaces with ocean, ice, and land models were run using offline data from 1 January 2000 through 31 December 2004. Number production fluxes based on parameterizations reported by Gong03 and Clk06 were simulated under the same set of conditions for comparison. Fields of chl- $a$ concentrations (in units of $\mathrm{mg} \mathrm{m}^{-3}$ ) in surface seawater were set equal to monthly averages derived from SeaWIFS imagery $\left(1^{\circ} \times 1^{\circ}\right.$, Gregg, 2008) for the period September 1997 through December 2002. Modeled size bins were centered on $0.039,0.076,0.15,0.52,2.4,4.9,15.1$ and $30-\mu \mathrm{m}$ diameters at $98 \%$ RH (i.e., within the laminar sub-layer immediately above the air-sea interface) across bin widths $\left(d D_{\mathrm{p}}\right)$ of $0.03,0.05,0.1,0.2,1.0,3.0,10.0$ and $20.0 \mu \mathrm{m}$, respectively. $\mathrm{RH}$ dependent diameter conversion from $98 \% \mathrm{RH}$ to those at $80 \%$ and $0 \% \mathrm{RH}$ was based on a $4: 2: 1$ ratio (Lewis and Schwartz, 2004). The non-linearity of the adsorption model used to associate particulate-OM to inorganic-sea-salt fluxes precludes explicit quantitative evaluation of corresponding uncertainty using linear uncertainty propagation laws. To evaluate the sensitivity of results to uncertainty in chl- $a$, 
Table 2. Adsorption parameters calculated from aerosol characteristics reported by Keene et al. (2007) and Facchini et al. (2008) and the corresponding mean chl- $a$ concentrations measured in seawater. Combined uncertainties are reported. Dashes indicate that a parameter is not applicable for an aerosol mode.

\begin{tabular}{lcc}
\hline Parameter & $\begin{array}{c}\text { Mode-1 Aerosol } \\
\text { (Eqs. 12 and 15) }\end{array}$ & $\begin{array}{c}\text { Mode-2 Aerosol } \\
\text { (Eq. 16) }\end{array}$ \\
\hline$B_{1}$ & $0.306 \pm 0.108$ & - \\
$\gamma_{\mathrm{m}, 1}$ & $-2.01 \pm 0.26$ & - \\
$\delta_{\mathrm{m}, 2}$ & - & $0.056 \pm 0.006$ \\
$k_{\mathrm{N}}$ & $40.0 \pm 29.3$ & $20.8 \pm 20.0$ \\
\hline
\end{tabular}

five-year simulations based on Long10 were repeated with $\log (\operatorname{chl}-a)=\log ($ mean chl- $a) \pm 0.31$ based on Gregg and Casey (2004).

\section{Results and discussion}

Size-resolved number production fluxes at $U_{10}$ of $9 \mathrm{~m} \mathrm{~s}^{-1}$ and $80 \%$ RH based on Long10 (at [chl- $a$ ] $=0.0$, i.e. no organic mass in the particles) are compared with those based on Mrt03 (for $25^{\circ} \mathrm{C}$ ), Gong03, and Clk06 in Fig. 2. Mrt03 measured size-resolved number concentrations of aerosols produced by bubbling air through synthetic seawater of unreported organic composition. Gong03 modified the original parameterization of Monahan et al. (1986) based on production fluxes inferred from thermal desorption measurements of size-resolved number concentrations of inorganic sea salt over the open ocean (O'Dowd et al., 1997). Clk06 inferred size-resolved production fluxes based on thermal desorption measurements of sea-salt number concentrations measured over a vertical gradient in a coastal surf zone. Note that the thermal desorption approach used in these latter two studies would have removed unknown but probably large fractions of the ambient $\mathrm{OM}_{\mathrm{aer}}$ prior to characterization. Mrt03, Gong03, and Clk06 extrapolated measured number size distributions as functions of $U_{10}$ over the ocean based on whitecap coverage using variants of the approach reported by Monahan and O'Muirchearteigh (1986). Because shapes of the size distributions on which the Long10, Mrt03, Gong03, and Clk06 parameterizations are based do not vary as functions of $U_{10}$, the corresponding relative variability in predicted size-resolved fluxes at $U_{10}$ greater and less than $9 \mathrm{~m} \mathrm{~s}^{-1}$ (not shown) is the same as that depicted in Fig. 2. Global average annual fluxes of number and mass as simulated with CAM based on Long10, Gong03, and Clk06 are summarized in Table 3. Upper and lower bounds of the CAM results for Long 10 are also reported.

In the size range between about 0.4 and $5.0 \mu \mathrm{m}$ diameter, predicted number production fluxes based on the four functions were statistically indistinguishable (Fig. 2), which im-

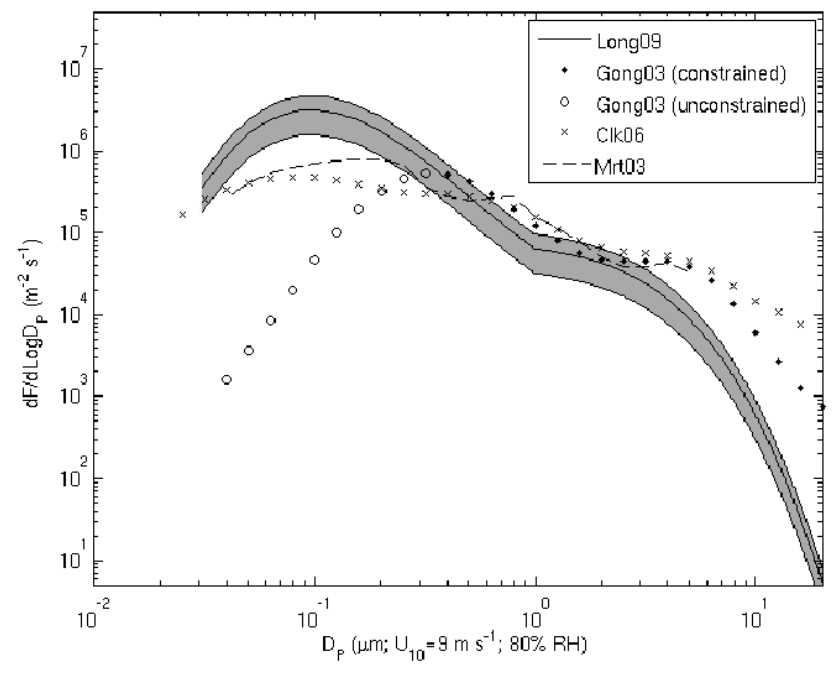

Fig. 2. Size-resolved number production fluxes based on Long10 compared with those based on Gong03, Clk06, and Mrt03 at 80\% $\mathrm{RH}$ and $U_{10}=9 \mathrm{~m} \mathrm{~s}^{-1}$. Because fluxes predicted by the other parameterizations are based on measurements of inorganic sea salt devoid of $\mathrm{OC}_{\mathrm{aer}}$ (see text), fluxes depicted for Long10 correspond to those at $0.0 \mathrm{mg}$ chl- $a \mathrm{~m}^{-3}$ (i.e. also devoid of $\mathrm{OC}_{\mathrm{aer}}$ ). The shaded area depicts combined measurement-based uncertainty associated with the entrainment of the bubble plume and particle production. Readers are referred to the cited literature for uncertainties associated with the other parameterizations. Open and closed circles for Gong03 depict predicted fluxes that are within and outside, respectively, the ranges of constraining measurement from which the function was derived.

plies that both the underlying measurements and the different approaches employed to scale number fluxes based on $U_{10}$ (white cap coverage versus air detrainment) yield representative results. We note that Gong03 and Clk06 scale with $U_{10}^{3.41}$ and Long 10 scales with $U_{10}^{3.74}$. In addition, the mean $U_{10}$ in the 5-yr CAM simulations was $8.2 \mathrm{~m} \mathrm{~s}^{-1}$ and relatively few $(\ll 1 \%)$ individual values were greater than $20 \mathrm{~m} \mathrm{~s}^{-1}$. Consequently, differences in scaling as functions of $U_{10}$ would introduce minor to negligible divergence in size-resolved production fluxes based on these functions. The significant divergence evident at the upper and lower ends of the sizeresolved flux distributions originates primarily from differences in the measured number size distributions rather than the corresponding scaling approaches.

Because mass flux is dominated by mode- 2 (super- $\mu \mathrm{m}$ diameter) aerosol, the relatively large divergence in predicted number production at the upper end of the size distribution ( $>5 \mu \mathrm{m}$ diameter, Fig. 2 ) accounts for virtually all of the divergence in average annual mass flux (Table 3 ). Two factors contribute to these differences: (1) large aerosols produced by spume drops that are injected directly into the atmosphere from the crests of breaking waves are not produced in bubbletype generators and, thus, were not considered by our parameterization. However, the parameterization of spume drop 
Table 3. Average annual emission fluxes of sea-salt mass, total aerosol number, and $\mathrm{OC}_{\mathrm{aer}}$ based on CAM (v3.5.07) simulations using different production parameterizations.

\begin{tabular}{lccc}
\hline Parameterization & $\begin{array}{c}\text { Sea-salt Mass Flux } \\
\left(\operatorname{Tg~y}^{-1}\right)\end{array}$ & $\begin{array}{c}\text { Number Flux } \\
\left(\mathrm{m}^{-2} \mathrm{~s}^{-1}\right)\end{array}$ & $\begin{array}{c}\text { OC }_{\text {aer Mass Flux }} \\
\left(\mathrm{Tg} \mathrm{C} \mathrm{y}^{-1}\right)\end{array}$ \\
\hline Long10 & $1.5\left( \pm 0.2^{\mathrm{a}} ; \pm 0.7^{\mathrm{b}}\right) \times 10^{3}$ & $1.4\left( \pm 0.2^{\mathrm{a}} ; \pm 0.7^{\mathrm{b}}\right) \times 10^{6}$ & $29\left( \pm 3^{\mathrm{a}} ; \pm 15^{\mathrm{b}} ; \pm 17^{\mathrm{c}}\right)$ \\
Gong03 & $5.9\left( \pm 0.8^{\mathrm{a}}\right) \times 10^{3}$ & $0.37\left( \pm 0.05^{\mathrm{a}}\right) \times 10^{6}$ & - \\
Clk06 & $20\left( \pm 2^{\mathrm{a}}\right) \times 10^{3}$ & $0.59\left( \pm 0.06^{\mathrm{a}}\right) \times 10^{6}$ & - \\
\hline
\end{tabular}

\footnotetext{
${ }^{a}$ Uncertainty corresponding to interannual variability in the simulated flux $(N=5)$.

b Combined uncertainty for interannual variability and measurements of aerosol characteristics (see text and summary in Table 4).

${ }^{\mathrm{c}}$ Combined uncertainty for interannual variability, measurements of aerosol characteristics, and satellite-based chl- $a$ fields (see text and summary in Table 4).
}

production can have a large influence on estimates of marine aerosol mass flux (Lewis and Schwartz, 2004; Fairall et al., 2009). (2) Production fluxes of aerosols produced by spume drops are poorly constrained by observation (e.g., Monahan and O'Muirchearteaigh, 1986; Andreas et al., 1995; Lewis and Schwartz, 2004; Fairall et al., 2009). Because of their large size, small surface-to-volume ratios and corresponding slow rates of chemical evolution, and short atmospheric lifetimes against deposition (hours) relative to smaller particles, spume-produced aerosols tend to have relatively minor influences in terms of biogeochemical processes and climatic impacts under many conditions. Although increasingly important at higher wind-speeds, theoretical and empirical constraints currently preclude reliable characterization of number and mass production fluxes of these large particles (Fairall et al., 2009). Because our parameterization does not include contributions from spume drops, corresponding mass fluxes are considered lower limits, which is consistent with the fact that the annual average mass flux based on Long10 (Table 3) is near the lower limit of published estimates $\left(1.3 \times 10^{3} \mathrm{Tg}^{-1}\right.$; e.g., Seinfeld and Pandis, 2006).

Simulated average annual number production fluxes, which are dominated by mode- 1 (sub- $\mu$ m-diameter) aerosols, varied over a factor of 4 (Table 3). However, the lowest number production fluxes correspond to Gong03 for which the lower end of measured size distribution is not constrained by observations (Fig. 2). We infer based on comparisons among the observationally constrained results that number production fluxes predicted by Gong03 may be underestimated. Average annual number fluxes predicted by Clk06 and Long 10 agree within a factor of $\sim 2.5$ (Table 3). Differences are driven by divergence at the lower end of the size distribution (Fig. 2) and may reflect real variability in aerosol production via coastal breaking waves versus bursting bubbles within a generator or possibly other methodological factors. In this regard, we note that number concentrations of sub$\mu \mathrm{m}$ diameter aerosols produced artificially by bubbling air through synthetic and natural seawater (Sellegri et al., 2008; Tyree et al., 2008) and by a water jet impinging on natural seawater (Hultin et al., 2010) yield normalized size distributions that are more similar to those reported by Keene et al. (2007). Additional measurements over a broader range of conditions are needed to constrain the current level of uncertainty in number production fluxes of marine aerosol evident in Table 3 and Fig. 2 and reported elsewhere (e.g., Andreas, 1995; Lewis and Schwartz, 2004).

For comparison with other published estimates, simulated $\mathrm{OM}_{\mathrm{aer}}$ masses were converted to equivalent $\mathrm{OC}_{\mathrm{aer}}$ masses based on an assumed conversion factor of 2.0 (Keene et al., 2007). The annual globally averaged $\mathrm{OC}_{\text {aer }}$ flux based on the bottom-up approach represented by Long $10\left(29 \mathrm{Tg} \mathrm{Cy}^{-1}\right)$ is within the range of estimates bounded by Gantt et al. (2009; $\left.22.3 \mathrm{Tg} \mathrm{C}^{-1}\right)$ and top-down estimates by Roelofs (2008; $35-50 \mathrm{Tg} \mathrm{C}^{-1}$ ) based on cloud droplet number and effective radii simulated with a fully coupled climate model as constrained by available measurements. In contrast, Spracklen et al. (2008) report a global production flux of $\mathrm{OC}_{\mathrm{aer}}$ originating from both primary and secondary sources of $8 \mathrm{Tg} \mathrm{Cy}^{-1}$ that is significantly lower than that bounded by total measurement uncertainty for data employed in our parameterization. This latter estimate, as well as that reported by Gantt et al. (2009), is inferred from linear fitting of data constrained by paired measurements of $\mathrm{OC}_{\mathrm{aer}}$ in marine air and chl- $a$ measured in moderate to highly productive waters. The low $\mathrm{OC}_{\mathrm{aer}}$ flux estimated by Spracklen et al. (2008) falls outside the range of expectations based on available observations. For example, a global emission flux of inorganic sea salt in the range of $10^{3}-10^{4} \mathrm{Tg} \mathrm{y}^{-1}$ (Table 3) and a mean $\mathrm{OM}_{\mathrm{aer}}$-to-sea-salt mass ratio of $2 \%-4 \%$ in nascent marine aerosol (e.g., Keene et al., 2007; Facchini et al., 2008) corresponds to a global emission flux of $\mathrm{OC}_{\mathrm{aer}}$ ranging from 10 $200 \mathrm{TgCy}^{-1}$, which brackets estimates based on Long10, Gantt et al. (2009), and Roelofs (2008) but is greater than that predicted by Spracklen et al. (2008). Conversely, an $\mathrm{OC}_{\mathrm{aer}}$ production flux of $<8 \mathrm{Tg} \mathrm{Cy}^{-1}$ in association with a sea-salt emission flux in the range of $10^{3}-10^{4} \mathrm{Tg}^{-1}$ yields a global

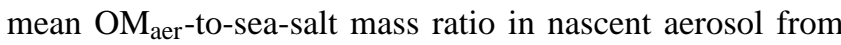
$<0.16 \%-<1.6 \%$, which is lower than the available, albeit limited, published measurements cited above 
Differences between estimates based on Long10, Gantt et al. (2009), and Spracklen et al. (2008) relate in part to the assumed functional relationship between $\mathrm{OC}_{\text {aer }}$ production and chl- $a$ in seawater as outlined conceptually in Fig. 3. The curve bounded by the light shaded area in Fig. 3 is based on adsorption isotherm parameters shown for bulk aerosol in Table 2. The aggregate value of the ratio of OM to seasalt, summed over the eight model size-bins and compiled from the model results is plotted as an open square in the figure; the agreement between this value and the global estimate based on bulk data and a global average chl- $a$ concentration is noteworthy. In Fig. 3, it is evident that $\mathrm{OC}_{\mathrm{aer}}$ production fluxes extrapolated linearly from surface chl- $a$ are highly sensitive to chl- $a$ concentrations in seawater from which the $\mathrm{OC}_{\mathrm{a}}$ originated. Assuming that the Langmuir functional relationship is representative, linear extrapolations based on measurements in productive marine regions (e.g. Facchini et al., 2008) would yield a relatively low $\mathrm{OM}_{\text {aer }}$ to chl- $a$ slope resulting in a net underestimate of the globally integrated $\mathrm{OM}_{\mathrm{aer}}$ flux (Fig. 4; dot-dashed straight line). Similarly, linear extrapolations based on measurements in oligotrophic waters (e.g. Keene et al., 2007) would yield a high $\mathrm{OM}_{\text {aer }}$ to chl- $a$ slope resulting in a net overestimate of the globally integrated $\mathrm{OM}_{\mathrm{aer}}$ flux (Fig. 4; dashed straight line). In this regard, we note that the range in $\mathrm{OM}_{\mathrm{aer}}$-to-sea-salt mass ratios inferred from both Spracklen et al. (2008) (Fig. 3; vertical bar) and Gantt et al. (2009) (not shown) overlap a linear extrapolation based on measurements in productive waters of the eastern North Atlantic by Facchini et al. (2008) (Fig. 3; dot-dashed straight line). A similar study by Vignati et al. (2010) used a linear extrapolation based on a revision of the OM-to-sea-salt relationship of O'Dowd et al. (2008), which yielded results consistent with Spracklen et al. (2008). The range in $\mathrm{OM}_{\mathrm{aer}}{ }^{-}$ to-sea-salt mass ratios inferred from Gantt et al. (2009) also overlaps the Langmuir-type approach presented here as depicted in Fig. 3.

The spatial distribution of $\mathrm{OC}_{\mathrm{aer}}$ production averaged over $5 \mathrm{yr}$ is plotted in Fig. 4, along with the corresponding distributions of $U_{10}$, chl- $a$ concentration, and number production flux. Relative spatial variability in mass flux (not shown) is very similar to that in number flux. Results from the global CAM simulations suggest that fluxes of $\mathrm{OC}_{\text {aer }}$ generally coincide with those for wind-driven particle and mass production though local maxima and minima in $\mathrm{OC}_{\mathrm{aer}}$ are associated with the distribution of chl- $a$. Validation of the simulated $\mathrm{OC}_{\mathrm{aer}}$ fluxes is constrained by both the limited availability of data for size-resolved, marine-derived $\mathrm{OC}_{\mathrm{aer}}$ (e.g., Turekian et al., 2003) and the fact that $\mathrm{OC}_{\text {aer }}$ associated with nascent marine aerosol is not conservative. The $\mathrm{OC}_{\mathrm{aer}}$ originally present includes compounds that react to form volatile products (Zhou et al., 2008) and aged aerosols include condensed organic reaction products from volatile precursors of marine, natural terrestrial, and anthropogenic origin (Turekian et al., 2003; de Gouw et al.; 2005; Meskhidze and Nenes, 2006; Russell et al., 2007).

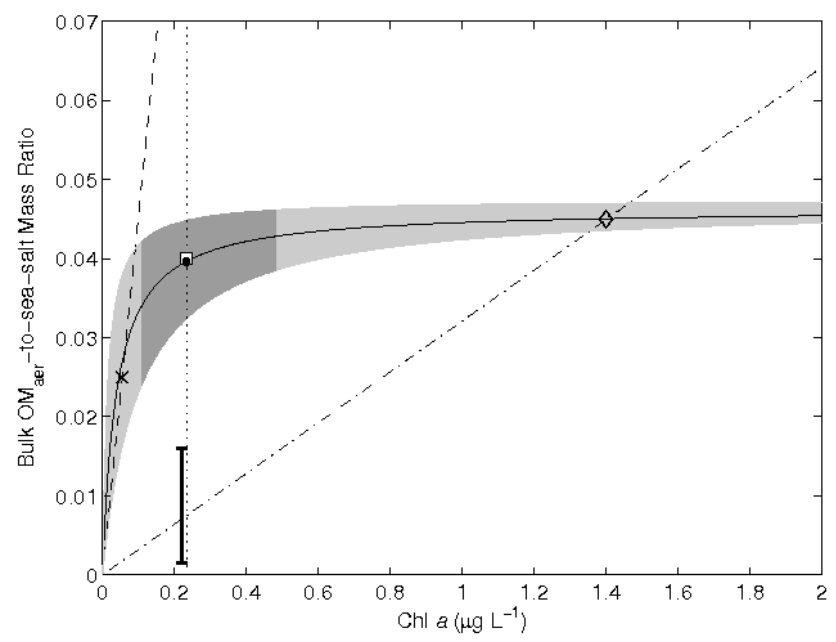

Fig. 3. Comparison of Langmuir versus linear extrapolations of the bulk $\mathrm{OM}_{\text {aer }}$ mass fraction of nascent marine aerosol as a function of chl- $a$ in seawater. The solid line depicts the fit of the mean $\mathrm{OM}_{\mathrm{aer}}$ data (Table 1) from low- (X; Keene et al. (2007) and highproductivity (diamond; Facchini et al., 2008) waters to a Langmuir model as described in the text. The gray shaded area depicts uncertainty around the fit associated with reported variability in the measured mass ratios of $\mathrm{OM}_{\mathrm{aer}}$ to sea salt (Table 1). The dark shaded area corresponds to uncertainty in the remotely sensed chl- $a$ data (see text). The dashed and dot-dashed lines depict linear extrapolations based on the mean results reported by Keene et al. (2007) and Facchini et al. (2008), respectively. The open square is the bulk $\mathrm{OM}_{\mathrm{aer}}$ mass fraction based on integration of results from the 5-yr CAM simulations using the Long10 parameterization and the solid circle is the corresponding bulk $\mathrm{OM}_{\mathrm{aer}}$ mass fraction calculated directly from the mean data in Table 1 . The vertical dotted line depicts the mean global chl- $a$ concentration $\left(0.23 \mu \mathrm{gL}^{-1}\right)$ based on the SeaWIFS data employed in this study. The vertical bar represents the range in the mass ratios of $\mathrm{OM}_{\mathrm{aer}}$ to sea salt that correspond to global $\mathrm{OC}_{\mathrm{aer}}$ (primary + secondary) emission fluxes of $8 \mathrm{Tg} \mathrm{Cy}^{-1}$ (Spracklen et al., 2008) based on a global inorganic seasalt emission flux of $10^{3}$ to $10^{4} \mathrm{Tg} \mathrm{y}^{-1}$ (Table 1) and a global mean chl- $a$ concentration of $0.22 \mathrm{mg} \mathrm{m}^{-3}$ (as inferred from results presented in Spracklen et al., 2008).

The novel parameterization presented herein is the first to predict the size- and composition-resolved production fluxes of marine aerosol over the full relevant size distribution. It is also the first to predict inorganic and organic marine aerosol fluxes based on an estimation of air entrainment by winddriven breaking waves. Simulated global production fluxes of primary marine aerosol number and $\mathrm{OC}_{\mathrm{aer}}$ are near the upper limits and those for mass are near the lower limit of the broad ranges of available estimates. As discussed above, this approach is based on limited observational constraints and will be refined as new data become available. In addition, the current lack of information precludes explicit evaluation of some important features of the system including the reliability of chl- $a$ as a proxy for $\mathrm{OM}_{\text {sea }}$, the contributions 


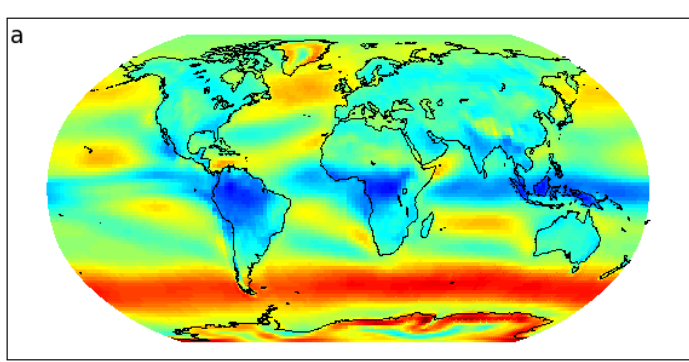

$U_{10}\left(\mathrm{~m} \mathrm{~s}^{-1}\right)$

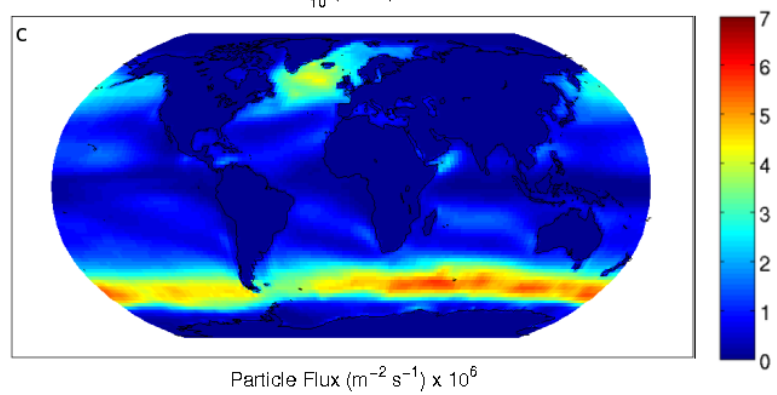

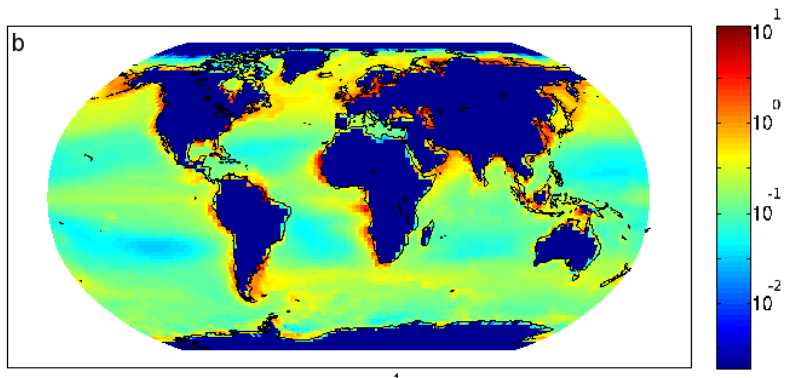

$\operatorname{chl} a\left(\mu \mathrm{g} \mathrm{L}{ }^{-1}\right)$

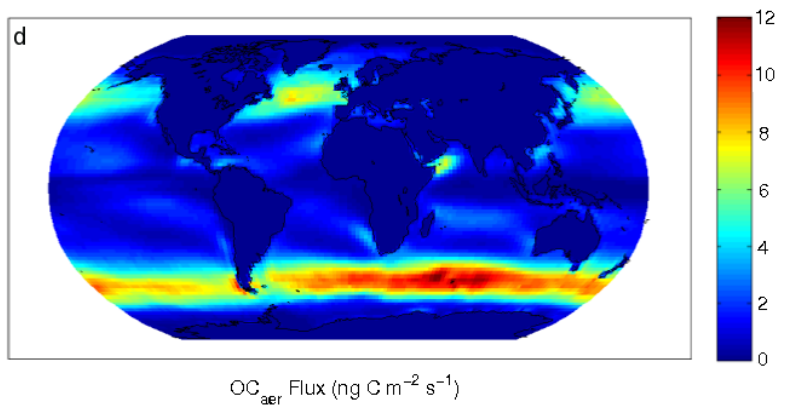

Fig. 4. Simulated spatial distributions of (a) $U_{10}$, (b) surface ocean chl- $a$, (c) total number production flux of nascent marine aerosol, and (d) the corresponding $\mathrm{OC}_{\mathrm{aer}}$ flux averaged over $5 \mathrm{yr}$.

of spume drops to aerosol mass production, and variability in aerosol production driven by bubble-plume dynamics that vary as functions of temperature (Mårtensson et al., 2003) and surfactants (Sellegri et al., 2006) that control surface tension over the open ocean, surface ocean dynamics (Hultin et al., 2010), and associated turbulent processes involved in bubble plume evolution (Deane and Stokes, 1999).

Major sources of uncertainty that contribute to overall uncertainty in results from the CAM simulations are summarized in Table 4. In addition, current limitations in Earth system models preclude explicit evaluation of air entrainment and particle production based on all factors that influence energy dissipation by breaking waves. For example, the simplified approach based on regression of $F_{\text {Ent }}$ versus $U_{10}$ as employed here does not capture the full range of variability in the functional relationship among wind velocity, sea state, air entrainment/detrainment, and resulting aerosol production. Extrapolations of aerosol production based on white-cap coverage as a function of $U_{10}$ suffer from similar limitations. Despite these limitations, the new parameterization reported herein represents an important advancement in efforts to characterize a major process in Earth's climate system based on the underlying physical and biological drivers. Simulated production fluxes of aerosol numbers and associated $\mathrm{OC}_{\mathrm{aer}}$ fall near the upper limits of published estimates If our estimate is correct, it suggests that primary marine aerosols have greater influences on the physicochemical evolution of the troposphere, radiative transfer and climate, and associated feedbacks on the surface ocean than suggested by previous model studies (e.g., Pierce and Adams, 2006).

\section{Summary}

The goals of this study were (1) to formulate a parameterization for primary marine aerosol production based on chemical and physical characteristics of aerosol generated under controlled conditions and the associated physical drivers, (2) to simulate global production fluxes of inorganic sea-salt mass, total particle number, and primary $\mathrm{OC}_{\mathrm{aer}}$, and (3) to interpret results in the context of corresponding estimates by other investigators. There were several key findings. (1) Simulated mass and number production fluxes based on air entrainment by breaking waves fell within the broad ranges of independent estimates extrapolated from whitecap area on the surface ocean. (2) Because the parameterization does not include aerosol production via spume drops, simulated mass fluxes are considered lower limits. (3) Number production fluxes were at the upper limit of the range of published estimates and, if representative, suggest that previous studies may underestimate influences of primary marine aerosol on radiative transfer and climate. (4) Available evidence suggests that the primary production flux of $\mathrm{OC}_{\mathrm{aer}}$ across the air-sea interface varies as a function of productivity in the surface ocean that is consistent with a theoretical framework based on a Langmuir equilibrium-type model. (5) The simulated global $\mathrm{OC}_{\mathrm{aer}}$ flux based on Long10 $\left(29 \pm 15 \mathrm{Tg} \mathrm{Cy}^{-1}\right)$ is within limits of published estimates $\left(<8\right.$ to $\left.50 \mathrm{Tg} \mathrm{Cy}^{-1}\right)$. (6) Variability in the production fluxes of marine aerosol mass, number, and primary $\mathrm{OC}_{\mathrm{aer}}$ are driven primary by the energy dissipated and associated air entrained via breaking ocean waves, which peak over the high-latitude southern 
Table 4. Summary of major sources of uncertainty in parameterization.

\begin{tabular}{|c|c|c|c|}
\hline Source & Uncertainty & Citation & Note \\
\hline $\begin{array}{l}\text { Air Entrainment } \\
\text { per Unit Energy }(\alpha)\end{array}$ & $\pm 25 \%$ & Various & See text \\
\hline $\begin{array}{l}\text { Whitecapping Energy } \\
\text { Dissipation Rate }\left(\varepsilon_{\mathrm{D}}\right)\end{array}$ & Unreported (est. $\pm 20 \%$ ) & Hanson and Phillips (1999) & See text \\
\hline Air Entrainment Volume $\left(F_{\text {Ent }}\right)$ & $\pm 40 \%^{\mathrm{a}}$ & This paper & See text \\
\hline $\begin{array}{l}\text { Measured Number } \\
\text { Production Flux }\end{array}$ & $\begin{array}{l}\text { Mode-1: } \pm 21 \% \\
\text { Mode-2: } \pm 84 \% \\
\text { Overall: } \pm 40 \%\end{array}$ & Keene et al. (2007) & $n=20^{\mathrm{b}}$ \\
\hline Measured $\mathrm{OM}_{\mathrm{aer}}$ & $\begin{array}{l}\text { Mode- } 1: \pm 12.2 \%^{\mathrm{b}} \\
\text { Mode-2: } \pm 73.3 \%^{\mathrm{b}}\end{array}$ & Keene et al. (2007) & $n=5$ \\
\hline Measured $\mathrm{OM}_{\mathrm{aer}}$ & $\begin{array}{l}\text { Mode-1: } \pm 4.4 \%^{\mathrm{b}} \\
\text { Mode-2: } \pm 4.4 \%^{\mathrm{b}}\end{array}$ & Facchini et al. (2008) & $n=9^{c}$ \\
\hline Chl $a$ & $10^{ \pm 31 \%}$ & Gregg and Casey (2004) & Log-normal RMS ${ }^{\mathrm{d}}$ \\
\hline Chl- $a$ vs. OM $_{\text {sea }}$ & $\begin{array}{l}\text { Unknown; } \\
\text { (Best estimate: } r^{2}=0.85 \text { ) }\end{array}$ & Zutic and Legovic (1990) & N. Adriatic Sea \\
\hline
\end{tabular}

a Estimated uncertainty corresponds to that at $U_{10}=9 \mathrm{~m} \mathrm{~s}^{-1}$.

${ }^{\mathrm{b}}$ Only samples with head-space $\mathrm{RH}=80 \% \pm 2 \%$. Values normalized by air-detrainment rate.

${ }^{\mathrm{c}}$ Reanalysis of published and unpublished data.

${ }^{\mathrm{d}}$ Root mean squared (RMS) error.

ocean. Future work stemming from this effort will couple the parameterization presented here with online modules of aerosol microphysics and detailed multiphase chemistry within the CCSM framework.

\section{Appendix A}

Final form of the parameterization. Intermediate equations and definitions are omitted for clarity. Constants are replaced by the values used in the simulations. Refer to Sect. 2 for details.

$$
\frac{d F_{\mathrm{N}}}{d \log D_{\mathrm{P}}}=F_{\mathrm{Ent}} \cdot 10^{P_{\mathrm{N}}}
$$

$F_{\text {Ent }}=2 \times 10^{-8} \cdot U_{10}^{3.74}$

$D_{\mathrm{P}}^{\prime}=\sqrt[3]{\frac{8}{8+\delta_{\mathrm{N}}}} \cdot D_{\mathrm{P}}$

For the mode-1 particle flux that accounts for variable OC (see Eqs. (9), (12), and (13) in the text):

$$
\begin{aligned}
& P_{1}\left(\log D_{\mathrm{P}}, \mathrm{OM} \mathrm{sea}\right)=1.46 \cdot\left(\log D_{\mathrm{P}}^{\prime}\right)^{3}+1.33 \cdot\left(\log D_{\mathrm{P}}^{\prime}\right)^{2} \\
& \quad-1.82 \cdot\left(\log D_{\mathrm{p}}^{\prime}\right)+8.83
\end{aligned}
$$

$$
\delta_{1}\left(D_{\mathrm{p}}, \mathrm{OM}_{\text {sea }}\right)=0.306 \cdot D_{\mathrm{P}}^{\gamma_{1}}
$$

$\gamma_{1}=\frac{-2.01 \cdot 40.0 \cdot[\mathrm{chl}-a]}{1+40.0 \cdot[\mathrm{chl}-a]}$

For the mode-2 particle flux (see Eqs. (7) and (14) in the text):

$$
\begin{gathered}
P_{2}\left(\log D_{\mathrm{P}}, \mathrm{OM}_{\text {sea }}\right)=-1.53 \cdot\left(\log D_{\mathrm{P}}^{\prime}\right)^{3}-8.10 \times 10^{-2} \\
\cdot\left(\log D_{\mathrm{P}}^{\prime}\right)^{2}-4.26 \times 10^{-1} \cdot\left(\log D_{\mathrm{P}}^{\prime}\right)+8.84
\end{gathered}
$$

$\delta_{2}=\frac{0.056 \cdot 20.8 \cdot[\mathrm{chl}-a]}{1+20.8 \cdot[\mathrm{chl}-a]}$ 


\section{Appendix B}

\section{Notation}

$B_{1} \quad$ empirical constant for size-resolved mode-1 OM content, unitless.

$c_{\mathrm{N}} \quad$ number production flux of mode- $\mathrm{N}$ aerosol per unit air detrained, $\mathrm{m}^{-3}$.

$D_{\mathrm{P}} \quad$ geometric mean diameter at $80 \% \mathrm{RH}, \mu \mathrm{m}$.

$D_{\mathrm{P}}^{\prime} \quad$ geometric mean diameter reflecting variable $V_{\mathrm{OC}}, \mu \mathrm{m}$.

$E_{\mathrm{D}} \quad$ total energy dissipated by wave-breaking, $\mathrm{J}$.

$f_{\mathrm{N}} \quad$ fitting function for mode- $\mathrm{N}$ aerosol based on $P_{\mathrm{N}}, \mathrm{m}^{-3}$.

$F_{\mathrm{N}} \quad$ size-resolved particle flux for mode-N aerosol, $\mathrm{m}^{-2} \mathrm{~s}^{-1}$.

$F_{\text {Det }} \quad$ bubble plume air detrainment flux, $\mathrm{m}^{3} \mathrm{~m}^{-2} \mathrm{~s}^{-1}$.

$F_{\text {Ent }} \quad$ bubble plume air entrainment flux, $\mathrm{m}^{3} \mathrm{~m}^{-2} \mathrm{~s}^{-1}$.

$F_{\mathrm{T}} \quad$ total particle number flux, $\mathrm{m}^{3} \mathrm{~m}^{-2} \mathrm{~s}^{-1}$.

$g \quad$ gravitational constant, $\mathrm{m} \mathrm{s}^{-2}$.

$K_{\mathrm{N}}$ empirically determined constant for mode-N aerosol based on $\mathrm{OM}_{\text {sea }}$, unitless.

$k_{\mathrm{N}} \quad$ empirically determined constant for mode- $\mathrm{N}$ aerosol based on chl- $a$, unitless.

$\mathrm{OC}_{\mathrm{aer}}$ particulate organic carbon mass, $\mathrm{g} \mathrm{C} \mathrm{m}^{-3}$.

$\mathrm{OM}_{\mathrm{aer}}$ particulate organic matter mass, $\mathrm{g} \mathrm{m}^{-3}$.

$\mathrm{OM}_{\text {sea }}$ surface-active organic matter in surface seawater, $\mathrm{g} \mathrm{m}^{-3}$.

$R_{\mathrm{N}} \quad$ diameter range for mode- $\mathrm{N}$ aerosols at $80 \% \mathrm{RH}$, $\mu \mathrm{m}$.

$U_{10} \quad$ windspeed at 10 -meter height, $\mathrm{m} \mathrm{s}^{-1}$.

$V_{0} \quad$ total volume of air entrained by a breaking wave, $\mathrm{m}^{3}$.

$V_{\mathrm{OM}} \quad$ volume of organic matter per particle, $\mu \mathrm{m}^{3}$.

$V_{\mathrm{P}} \quad$ total volume per particle at $80 \% \mathrm{RH}, \mu \mathrm{m}^{3}$.

$V_{\mathrm{SS}} \quad$ volume of inorganic sea salt per particle at $0 \%$ $\mathrm{RH}, \mu \mathrm{m}^{3}$.

$\alpha \quad$ ratio of $V_{0}$ to $E_{\mathrm{D}}, \mathrm{m}^{3} \mathrm{~J}^{-1}$.

$\gamma_{1} \quad$ Langmuir-based shape parameter for mode-1 aerosol, unitless.

$\gamma_{\mathrm{m}, 1} \quad$ saturation value for mode-1 aerosol shape parameter, unitless.

$\delta_{\mathrm{m}, 2} \quad$ saturation value for volume ratio of organic matter to dry sea salt for mode-2 aerosol, unitless.

$\delta_{\mathrm{N}} \quad$ volume ratio of organic matter to dry sea salt for mode- $\mathrm{N}$ aerosol, unitless.

$\varepsilon_{\mathrm{D}} \quad$ wind-wave energy dissipation rate, $\mathrm{W} \mathrm{m}^{-2}$.

$\omega \quad$ ratio of deliquesced-to-dry-sea-salt diameter at $80 \% \mathrm{RH}$, unitless.

\section{Supplementary material related to this article is available online at: \\ http://www.atmos-chem-phys.net/11/1203/2011/ acp-11-1203-2011-supplement.pdf.}

Acknowledgements. We thank M. C. Facchini for helpful discussions and for providing unpublished data. We also thank C. Fairall and C. Blenkinsopp for constructive comments regarding wind-waves and air entrainment. Staff and scientists at the ORNL Computational Science and Mathematics Division (P. Worley), the Pacific Northwest National Laboratory Atmospheric Science and Global Change Division (S. Ghan, X. Liu), and the Max Planck Institute for Chemistry's Atmospheric Chemistry Department (A. Kerkweg, P. Jockel, R. Sander) provided valuable assistance. We also acknowledge the contribution of processed SeaWIFS chl- $a$ data by W. Gregg of NASA's Goddard Space Flight Center. The Marine and Atmospheric Chemistry Research Laboratory at the University of North Carolina at Wilmington also provided analytical facilities and assistance. Financial support was provided by the U.S. Department of Energy's Office of Science through the Office of Biological and Environmental Research (grant number DE-FG02-07ER64442 to UVA), a Global Change Education Program Graduate Research Environmental Fellowship, and the National Center for Computational Sciences at Oak Ridge National Laboratory (ONRL, contract DE-AC05-00OR22725). Additional support was provided by the National Science Foundation through awards ATM-0343146 and ATM-0638741 to UVA and ATM 0343199 to SUNY.

Edited by: E. Vignati

\section{References}

Andreae, M. O. and Rosenfeld, D.: Aerosol-cloud-precipitation interactions. Part 1. The nature and sources of cloud-active aerosols, Earth Sci. Rev., 89, 13-41, 2008.

Andreas, E. L., Edson, J. B., Monahan, E. C., Rouault, M. P., and Smith, S. D.: The spray contribution to net evaporation from the sea: A review of recent progress, Bound.-Lay. Meteorol., 72, 352, 1995.

Blenkinsopp, C. E. and Chaplin, J. R.: Void fraction measurements in breaking waves. Proc. Royal Soc. A, 463(2088), 3151-3170, 2007.

Carlson, C. A., Ducklow, H. W., and Michaels, A. F.: Annual flux of dissolved organic carbon from the euphotic zone in the northwestern Sargasso Sea, Nature, 371, 405-408, 1994.

Chameides, W. L. and Stelson, A. W.: Aqueous-phase chemical processes in deliquescent sea salt aerosols: A mechanism that couples the atmospheric cycles of S and sea salt, J. Geophys. Res., 97, 20565-20580, 1992.

Clarke, A. D., Owens, S. R., and Zhou, J.: An ultrafine sea salt flux from breaking waves: Implications for cloud condensation nuclei in the remote marine atmosphere, J. Geophys. Res., 111, D06202, doi:10.1029/2005JD006565, 2006.

Deane, G. B.: Sound generation and air entrainment by breaking waves in the surf zone, J. Acoust. Soc. Am., 102(5), 2671-2689, 1997. 
Deane, G. B. and Stokes, M. D.: Entrainment processes and bubble size distributions in the surf zone, J. Geophys. Res., 29, 13931403, 1999.

Decesari, S., Facchini, M. C., Mircea, M., Cavalli, F., Emblico, L., Fuzzi, S., Moretti, F., and Tagliavini, E.: Source attribution of water-soluble organic aerosol by nuclear magnetic resonance spectroscopy, Environ. Sci. Technol., 41, 2479-2484, 2007.

de Gouw, J. A., Middlebrook, A. M., Warneke, C., Goldan, P. D., Kuster, W. C., Roberts, J. M., Fehsenfeld, F. C., Worsnop, D. R., Canagaratna, M. R., Pszenny, A. A. P., Keene, W. C., Marchewka, M., Bertman, S. B., and Bates, T. S.: Budget of organic carbon in a polluted atmosphere: Results from the New England Air Quality Study in 2002, J. Geophys. Res., 110, D16305, doi:10.1029/2004JD005623, 2005.

Doval, M. and Hansell, D. A.: Organic carbon and apparent oxygen utilization in the western South Pacific and central Indian Oceans, Mar. Chem., 68, 249-264, 2000.

Erickson, D. J., Seuzaret, C., Keene, W. C., and Gong, S.-L.: A general circulation model calculation of $\mathrm{HCl}$ and $\mathrm{ClNO}_{2}$ production from sea salt dechlorination: Reactive Chlorine Emissions Inventory, J. Geophys. Res., 104, 8347-8372, 1999.

Facchini, M. C., Rinaldi, M., Decesari, S., Carbone, C., Finessi, E., Mircea, M., Fuzzi, S., Ceburnis, D., Flanagan, R., Nilsson, E. D., de Leeuw, G., Martino, M., Woeltjen, J., and O'Dowd, C. D.: Primary submicron marine aerosol dominated by insoluble organic colloids and aggregates, Geophys. Res. Lett., 35, L17814, doi:10.1029/2008GL034210, 2008.

Fairall, C. W., Banner, M. L., Peirson, W. L., Asher, W., and Morison, R. P.: Investigation of the physical scaling of sea spray spume droplet production, J. Geophys. Res., 114, C10001, doi:10.1029/2008JC004918, 2009.

Felizardo, F. C. and Melville, W. K.: Correlations between ambient noise and the ocean surface wave field, J. Phys. Oceanogr., 25, 513-532, 1995.

Fuentes, E., Coe, H., Green, D., de Leeuw, G., and McFiggans, G.: Laboratory-generated primary marine aerosol via bubblebursting and atomization, Atmos. Meas. Tech., 3, 141-162, doi:10.5194/amt-3-141-2010, 2010.

Gantt, B., Meskhidze, N., and Kamykowski, D.: A new physically-based quantification of marine isoprene and primary organic aerosol emissions, Atmos. Chem. Phys., 9, 4915-4927, doi:10.5194/acp-9-4915-2009, 2009.

Geever, M., O’Dowd, C. D., van Ekeren, S., Flanagan, R., Nilsson, E. D., de Leeuw, G., and Rannik, U.: Submicron sea spray fluxes, Geophys. Res. Lett., 32, L15810, doi:10.1029/2005GL023081, 2005.

Gent, P. R., Yeager, S. G., Neale, R. B., Levis, S., and Bailey, D. A.: Improvements in a half degree atmosphere/land version of the CCSM, Clim. Dynam., 34(6), 819-833, doi:10.1007/s00382009-0614-8, 2009.

Ghosh, P.: Coalescence of air bubbles at air-water interface, Chem. Eng. Res. Des., 82, 849-854, 2004.

Giribabu, K. and Ghosh, P.: Adsorption of nonionic surfactants at fluid-fluid interfaces: importance in the coalescence of bubbles and drops, Chem. Eng. Sci., 62, 3057-3067, 2007.

Gong, S. L.: A parameterization of sea salt aerosol source function for sub- and super-micron particles, Global Biogeochem. Cy., 17, 1097, doi:10.1029/2003gb002079, 2003.

Gong, S. L., Barrie, L. A., and Lazare, M.: Canadian Aerosol
Module (CAM): A size-segregated simulation of atmospheric aerosol processes for climate and air quality models 2 . Global sea-salt aerosol and its budgets, J. Geophys. Res., 107, 4779, doi:10.1029/2001JD002004, 2002.

Gregg, W. W.: Assimilation of SeaWIFS global ocean chlorophyll data into a three-dimensional global ocean model, J. Mar. Sys., 69, 205-225, 2008.

Gregg, W. W. and Casey, N. W.: Global and regional evaluation of the SeaWiFS chlorophyll Data Set, Remotr Sens. Environ., 93, 463-479, 2004.

Hanson, J. L. and Phillips, O. M.: Wind sea growth and dissipation in the open ocean, J. Phys. Oceanogr., 29(8), 1633-1648, 1999.

Hoffman, E. J. and Duce, R. A.: Factors influencing the organic carbon content of marine aerosols: A laboratory study, J. Geophys. Res., 81, 3667-3670, 1976.

Hoque, A.: Air Bubble Entrainment by Breaking Waves and Associated Energy Dissipation, Ph.D. Thesis. Toyohashi University of Technology, 2002.

Hultin, K. A. H., Nilsson, E. D., Krejci, R., Mårtinsson, E. M., Ehn, K., Hagström, Å., and de Leeuw, G.: In situ laboratory sea spray production during the MAP 2006 cruise on the North East Atlantic, J. Geophys. Res., 115, D06201, doi:10.1029/2009JD012522, 2010.

James, C. and Lang, S. P.: Truncating criteria for polynomial curve fitting, J. Phys. D: Appl. Phys., 4, 357-363, 1971.

Keene, W. C., Maring, H., Kieber, D. J., Maben, J. R., Pszenny, A. A. P., Dahl, E. E., Izaguirre, M. A., Davis, A. J., Long, M. S., Zhou, X., Smoydzin, L., von Glasow, R., and Sander, R.: Chemical and physical characteristics of nascent aerosols produced by bursting bubbles at a model air-sea interface, J. Geophys. Res., 112, D21202, doi:10.1029/2007JD008464, 2007.

Lamarre, E. and Melville, W. K.: Air entrainment and dissipation in breaking waves, Nature, 351, 469-472, 1991.

Langmann, B., Scannell, C., and O'Dowd, C.: New directions: Organic matter contribution to marine aerosols and cloud condensation nuclei, Atmos. Environ., 42, 7821-7822, 2008.

Lewis, R. and Schwartz, S. E.: Sea Salt Aerosol Production: Mechanisms, Methods, Measurements, and Models - A Critical Review, Geophysical monograph 152, 413 pp., American Geophysical Union, Washington, DC, 2008.

Loewen, M. R. and Melville, W. K.: An experimental investigation of the collective oscillations of bubble plumes entrained by breaking waves, J. Acoust. Soc. Am., 95, 1329-1343, 1993.

Mårtensson, E. M., Nilsson, E. D., deLeeuw, G., Cohen, L. H., and Hansson, H.-C.: Laboratory simulations and parameterization of the primary marine aerosol production, J. Geophys. 5 Res., 108, 4297, doi:10.1029/2002JD002263, 2003.

Melville, W. K. and Rapp, R. J.: Momentum Flux in Breaking Waves, Nature, 317, 514-516, 1985.

Meskhidze, N. and Nenes, A.: Phytoplankton and cloudiness in the southern ocean, Science, 314, 1419-1423, 2006.

Modini, R. L., Harris, B., and Ristovski, Z. D.: The organic fraction of bubble-generated, accumulation mode Sea Spray Aerosol (SSA), Atmos. Chem. Phys., 10, 2867-2877, doi:10.5194/acp10-2867-2010, 2010.

Monahan, E. C. and O'Muircheartaigh, I. G.: Whitecaps and the passive remote-sensing of the ocean surface, Int. J. Remote Sens., 7, 627-642, 1986.

Monahan, E. C., Spiel, D. E., and Davidson, K. L.: A model of 
marine aerosol generation via whitecaps and wave disruption, in: Oceanic Whitecaps, edited by: Monahan, E. and Niocaill, G. M., 167-174, D. Reidel, Norwell, Mass, 1986.

O’Dowd, C. D., Smith, M. H., Consterdine, I. E., and Lowe, J. A.: Marine aerosol, sea-salt, and the marine sulphur cycle: A short review, Atmos. Environ., 31, 73-80, 1997.

O’Dowd, C. D., Facchini, M. C., Cavalli, F., Cebrunis, D., Mircea, M., Decesari, S., Fuzzi, S., Yoon, Y. J., and Putard, J.-P.: Biogenically driven organic contribution to marine aerosol, Nature, 431, 676-680, 2004.

O’Dowd, C. D., Langmann, B., Varghese, S., Scannell, C., Ceburnis, D., and Facchini, M. C.: A combined organic-inorganic sea-spray source function, Geophys. Res. Lett., 35, L01801, doi:10.1029/2007GL030331, 2008.

Pierce, J. R. and Adams, P. J.: Global evaluation of CCN formation by direct emission of sea salt and growth of ultrafine sea-salt, J. Geophys. Res., 111, D06203, doi:10.1029/2005JD006186, 2006.

Roelofs, G. J.: A GCM study of organic matter in marine aerosol and its potential contribution to cloud drop activation, Atmos. Chem. Phys., 8, 709-719, doi:10.5194/acp-8-709-2008, 2008.

Russell, L. M., Mensah, A. A., Fischer, E. V., Sive, B. C., Varner, R. K., Keene, W. C., Stutz, J., and Pszenny, A. A. P.: Nanoparticle growth following photochemical $\alpha$ - and $\beta$-pinene oxidation at Appledore Island during International Consortium for Research on Transport and Transformation/Chemistry of Halogens at the Isles of Shoals 2004, J. Geophys. Res., 112, D10S21, doi:10.1029/2006JD007736, 2007.

Scatchard, G.: Equilibrium thermodynamics and biological chemistry, Science, 95, 27-32, 1942.

Schkolnik, G., Chand, D., Hoffer, A., Andreae, M., Erlick, C., Swietlicki, E., and Rudich, Y.: Constraining the density and complex refractive index of elemental and organic carbon in biomass burning aerosol using optical and chemical measurements, EOS Trans. AGU, 87(52), Fall Meeting Suppl., Abstract A43A-0107, 2006.

Seinfeld, J. H. and Pandis, S. N.: Atmospheric Chemistry and Physics: from air pollution to climate change -2 nd ed., John Wiley and Sons, Inc., Hoboken, 2006.

Sellegri, K., O’Dowd, C. D., Yoon, Y. J., Jennings, S. G., and de Leeuw, G.: Surfactants and submicron sea spray generation, J. Geophys. Res., 111, D22215, doi:10.1029/2005JD006658, 2006.

Spracklen, D. V., Arnold, S. R., Carslaw, K. S., Sciare, J., and Pio, C.: Globally significant oceanic source of organic carbon aerosol, Geophys. Res. Lett., 35, L12811, doi:10.1029/2008GL033359, 2008.

Stefan, R. L. and Szeri, A. J.: Surfactant scavenging and surface deposition by rising bubbles, J. Coll. Interface Sci., 212, 1-13, 1999.
Stumm, W. and Morgan, J. J.: Aquatic Chemistry, Chemical Equilibria and Rates in Natural Waters, 3rd ed., 1022 pp., John Wiley \& Sons, Inc., New York, 1996.

Thorpe, S. A.: On the cloud of bubbles formed by a breaking windwave in deep water, and their role in air-sea gas transfer, Philos. T. Royal Soc. London, 304A, 155-210, 1982.

Toba, Y., Okada, K., and Jones, I. S. F.: The response of wind-wave spectra to changing winds. Part 1: Increasing winds, J. Phys. Oceanogr., 18, 1231-1240, 1988.

Tseng, R.-S., Viechnicki, J. T., Skop, R. A., and Brown, J. W.: Seato-air transfer of surface-active organic compounds by bursting bubbles, J. Geophys. Res., 97, 5201-5206, 1992.

Turekian, V., Macko, S. A., and Keene, W. C.: Concentrations, isotopic compositions, and sources of size-resolved, particulate organic carbon and oxalate in near-surface marine air at Bermuda during spring, J. Geophys. Res., 108, D4157, doi:10.1029/2002JD002053, 2003.

Turpin, B. J. and Lim, H.: Species contributions to PM2.5 mass concentrations: Revisiting common assumptions for estimating organic mass, Aerosol Sci. Technol., 35, 602-610, 2010.

Tyree, C. A., Hellion, V. M., Alexandrova, O. A., and Allen, J. O.: Foam droplets generated from natural and artificial seawaters, J. Geophys. Res., 112, D12204, doi:10.1029/2006JD007729, 2007.

Vignati, E., Facchini, M. C., Rinaldi, M., Scannell, C., Ceburnis, D., Sciare, J., Kanakidou, M., Myriokefalitakis, S., Dentener, F., and O'Dowd, C. D.: Global scale emission and distribution of sea spray aerosol: sea-salt and organic enrichment, Atmos. Environ., 44, 670-677, doi:10.1016/j.atmosenv.2009.11.013, 2009.

von Glasow, R. and Crutzen, P. J.: Model study of multiphase DMS oxidation with a focus on halogens, Atmos. Chem. Phys., 4, 589608, doi:10.5194/acp-4-589-2004, 2004.

Zhou, X., Davis, A. J., Kieber, D. J., Keene, W. C., Maben, J. R., Maring, H., Dahl, E. E., Izaguirre, M. A., Sander, R., and Smoydzyn, L.: Photochemical production of hydroxyl radical and hydroperoxides in water extracts of nascent marine aerosols produced by bursting bubbles from Sargasso seawater, Geophys. Res. Lett., 35, L20803, doi:10.1029/2008GL035418, 2008.

Zutic, V. and Legovic, T.: Relationship between phytoplankton blooms and dissolved organic matter in the northern Adriatic, in Final Reports on Research Projects Dealing with Eutrophication and Plankton Blooms (Activity H), MAP Technical Reports Series no. 37, 53-66, United Nations Environment Programme (UNEP), Athens (Greece), 1990. 